\title{
Empowering Senior Citizens in Leisure Settings Through Mediation: Becoming a Mediator
}

\author{
Immaculada Armadans, Nuria Codina, and José V. Pestana \\ Department of Social Psychology, Campus Mundet, University of Barcelona, Barcelona, Spain
}

\begin{abstract}
Empowering senior citizens helps to preserve optimal physical, mental, and social activity among this age group. It helps them grow old successfully. The development of the mediator figure is an educational opportunity for the senior citizens and their social environment, and it contributes to the promotion of the mediation culture. Thus, this study aims to explain the implementation of a program and its results, a program that seeks to develop the "senior citizens" figure and to empower senior users of leisure facilities with basic social skills. The results were obtained from three senior centers and a total of 32 subjects that followed the training, 21 of which asked to keep spreading the culture of mediation. The main results show a significant improvement of their skills regarding conflict understanding, communication, and handling of conflict situations. Furthermore, 21 of the participants made and implemented 11 projects of social actions in the communities where they live. In addition, the program was evaluated as highly satisfactory. These findings show the effects of this kind of educational program, which predict future possibilities for mediation in senior citizens from an educational perspective.
\end{abstract}

In a situation of successful aging, it is crucial for the senior citizen to develop an active, participative, and autonomous attitude within a healthy lifestyle that integrates physical, mental, and social activities (Luppi, 2009, 2010). Concerning the last, we have seen that older people need to improve their ability to adapt to psychosocial aging, as well as their ability to face difficult situations. This is because these challenges are often the result of disempowerment, insecurity, and social exclusion (Ogg, 2005). We notice that one of the best interventions consists of empowering seniors through specific educational programs (Maxwell, 1997; Ogg, 2005), which usually leverage the great development and learning potential that comes with maturity (Bernard, 2009).

Empowering of senior citizens aims basically at giving them greater control over their own lives and due prominence in decision making in their communities and in the organizations they belong to (Cusack, 1998: 1999). Specifically, being empowered gives them the psychological resources to face the inevitable conflict linked to the last stage of the biological cycle (Bowman, 2000; Bloche, 2005), thus contributing to their social inclusion and their involvement as full-righted citizens (Fenge, 2006, 2010).

The active senior citizen often participates in the activities offered in different settings and/or leisure centers, basically focused on the promotion and preservation of successful aging

Address correspondence to Immaculada Armadans, Department of Social Psychology, Campus Mundet, University of Barcelona, Passeig de la Vall d'Hebron 171, Ed. de Ponent, 08035 Barcelona, Spain. E-mail: iarmadans@ub.edu 
(Nimrod, 2007; Kleiber, Walker, \& Mannel, 2011; Codina, Pestana \& Armadans, 2013). These environments allow elder people who are surrounded by a free-choice, satisfactory, and pleasurable entourage, to be more responsive to the educational and training challenges suggested by the intervention agents in general and, consequently, turns these unto the ideal context in which empowerment can be developed (Walter, Schneider, \& Plaumann, 2008; Marhánkova, 2010). In this sense, it is important to emphasize that leisure is a powerful contributor to psychological empowerment (Zimmerman, Israel, Schulz, \& Checkoway, 1992) and that, specifically, activity offered in leisure centers is focused in such a manner that senior citizens experience the value and the personal and social usefulness of leisure. They also learn relevant concepts, recover values, and develop new and active social roles (Morata \& Palassí, 2012).

Among the different educational or empowering options, conflict mediation in senior citizens can represent a good option (Kardasis \& Dugan, 2004; Baruch \& Folger, 2005) that allows them to improve social involvement, person-to-person relationship management, and socializing in the community (Cobb, 1993; Costa \& Silva, 2012). Mediation -understood as a peaceful method of alternate conflict solving, where a third, "neutral" party or with a third-side position (Ury, 1999) enables two or more parties to find a solution to their conflicts through dialogue - produces results when social skills are developed in the figure of the mediator (Wall, Stark, \& Standifer, 2001, 2012). Furthermore, from the peace culture paradigm, the existence of social or natural helper figures in the community is favored (Lederach, 1998). This is because these figures are able to transform conflict situations into opportunities to build social relationships in a peaceful way; thus, they are able to build and strengthen social networks in different communities.

However, when senior citizens are involved, mediation requires a special approach that takes into account the reality of old age, the socioeconomic changes, and the problems linked to that last stage of the biological cycle. In that sense, mediation should try to balance the physical, the psychological, and the social aspects if it wants to be useful and respond to the needs of this age-group and its main problems (Gary, 1997; Schmitz, 1998; Bertschler \& Cocklin, 2004). Along these lines, Craig (2000) emphasizes the contribution made by intergenerational mediation to prevent situations of abuse towards senior citizens. And Munuera Gómez (2006) and Munuera Gómez and Rondón García (2010) point out to mediation's contribution in the management of conflicts produced by dependence situations. From an educational point of view, we can find studies that emphasize the importance of developing communication and negotiation competences (Schmitz, 1998; Bowman, 2000; Armadans, 2009; Alzate, Malla, \& Godoy, 2009). There is also the acquisition of positive benefits and satisfaction when voluntary mediators are trained to assist other older mediators (Cox \& Parsons, 1992).

For all the above, in the present study we suggest that empowering educational programs through conflict mediation (Cobb, 1993), when implemented in a leisure environment, must provide knowledge and develop essential resources and skills for the practice of mediation. The kinds of abilities that the mediator must basically develop in order to intervene in a conflict situation are linked to essential conflict understanding abilities, person-to-person abilities, and instrumental and systemic abilities (Boqué, 2013); personal power and social interaction management and the development of neutrality or impartiality before conflict situations (Cobb, 1993). Also worth mentioning is the well-known fact that, in conflict situations, mediators have power, they help people to better communicate, to change positions and focus toward agreement, and to get satisfaction out of interpersonal relationships (Baruch \& Folger, 1994; Agusti-Panareda, 2005). Furthermore, through the implementation of conflict mediation 
programs, there are several contexts in which senior citizens (Armadans, 2009; Armadans et al., 2010) can help transform and prevent conflict, along the lines suggested by Ury (1999). Seniors can do so when they are trained in positive conflict management and in the acquisition of social and communication skills that they can apply in social and day-to-day cohabitation; thus, they benefit from social inclusion and social involvement.

From these theoretical considerations, we considered as a crucial part of this study the exploration, through an experimental study, of the possibility to effectively demonstrate that senior citizens can be empowered, that they can learn and develop basic mediation skills in a leisure and spare time context. That's why this intervention program applies basic skills for the development of an appropriate understanding and positive conflict management. It also applies the promotion of basic communication and social skills, and the enhancement of mediation to act in day-to-day and social conflicts. It does this by developing a natural senior citizen figure who can be capable of undertaking social mediating activities in his/her community, adopting a peace culture attitude.

\section{METHODOLOGY}

\section{Participants (Sample)}

For this study, we had the participation of 32 people (10 male and 22 female) from a 49-83 age-group $(M=65.46 ; S D=8.44)$. Participants were selected through a nonprobability opportunity sampling among users of three leisure centers for senior citizens. Nine participants came from a center in Barcelona, 8 from Manresa and 15 from Santa Coloma de Gramanet. The selection requirements for admittion in the program were the following: at least 50-years old, expressing a free-will decision to engage in the program, and showing motivation towards conflict management and mediation in his/her own community. These were the general sociodemographic features of participants: living in suburban areas (43.8\%); urban areas $(31.3 \%)$; living with a partner $(43.8 \%)$; declared income level, medium (50.0\%); education level, primary $(56.3 \%)$; and $50.0 \%$ were retired. Most indicated that they were in good health $(71.9 \%)$ (see Table 1$)$.

\section{Materials and Procedure}

The intervention program Senior Mediator (Armadans, Vilaseca, \& Quesada, 2010) was applied. This is a custom-made program for a social organization (involved in the management of leisure centers). This organization requested the possibility to create a natural senior mediators social network whose members should ideally be the participants in the program. The program's theoretical grounds were based on developing in the participants a conflict vision from a peace culture standpoint (Lederach, 1998). The program starts with the development of a senior mediator figure who learns basic social communication skills who, from a third-party position, intervenes in the conflict management by easing the agreement with others (Ury, 1999). Lederach (2000) also assumes that conflict represents an interaction between two adversaries who defend their own interests and who need help to reach an agreement, which is positive in terms of personal growth.

Furthermore, the theoretical contents and the educational methodologies were designed to leverage the great development and learning power linked to maturity (Bernard, 2009). 
TABLE 1

Sociodemographic Characteristics $(N=32)$

\begin{tabular}{|c|c|c|}
\hline & $\mathrm{N}$ & $\%$ \\
\hline \multicolumn{3}{|l|}{ Living arrangements } \\
\hline With a partner & 14 & 43.8 \\
\hline With children & 5 & 15.6 \\
\hline With a partner and children & 3 & 9.4 \\
\hline With parents & 1 & 3.1 \\
\hline With housemates & 1 & 3.1 \\
\hline Living alone & 2 & 6.3 \\
\hline No response & 6 & 18.8 \\
\hline \multicolumn{3}{|l|}{ Living area } \\
\hline Suburban & 14 & 43.8 \\
\hline Urban & 10 & 31.3 \\
\hline Rural & 1 & 3.1 \\
\hline Rural-urban & 1 & 3.1 \\
\hline No response & 6 & 18.8 \\
\hline \multicolumn{3}{|l|}{ Income level } \\
\hline Medium & 16 & 50.0 \\
\hline Medium-low & 9 & 28.1 \\
\hline Medium-high & 1 & 3.1 \\
\hline No response & 6 & 18.8 \\
\hline \multicolumn{3}{|l|}{ Education } \\
\hline Primary/middle school & 18 & 56.3 \\
\hline High school & 1 & 3.1 \\
\hline College/university degree & 7 & 21.9 \\
\hline No response & 6 & 18.8 \\
\hline \multicolumn{3}{|l|}{ Working situation } \\
\hline Active & 3 & 9.4 \\
\hline Non active & 4 & 12.5 \\
\hline Retired & 16 & 50.0 \\
\hline Early retirement & 3 & 9.4 \\
\hline No response & 6 & 18.8 \\
\hline \multicolumn{3}{|l|}{ Health } \\
\hline Good & 23 & 71.9 \\
\hline Some problems (not affecting autonomy) & 3 & 9.4 \\
\hline No response & 6 & 18.8 \\
\hline
\end{tabular}

The program adopted a methodology focused on direct, reflective, and participative teachings (Hedeen, Raines, \& Barton, 2010) based on group learning among equals, through playful strategies. This methodology not only helps absorb knowledge, but also, and above all, individuals manage to change their attitudes, develop their abilities, and transform their behavior. Thus, they become active change agents.

The educational program tried to assure that the participants interested in mediation, could also do the following,

- Understand and see conflict as something useful in people's lives.

- Learn managing and resolution strategies of positive conflict. 
- Practice communication strategies for conflict management.

- Promote mediation knowledge in order to act and get along with other people.

- Encourage activities to promote mediation.

Additionally, we also wanted to know the satisfaction level this kind of program could produce among senior citizens.

We structured the program around the following stages:

\section{Stage I: Condition Creation}

Stage I consisted of raising awareness in leisure centers about the benefits of joint participation in the organization and management of the program. Thus, several visits were made to these centers in order to prepare a first, open doors session. In this session we introduced the participants to mediation and its context and to the contents and goals of the educational program. We also wanted to ease the voluntary access to the program, to recruit participants, and to gather the first data about their origin and interests. From this first session, we obtained the 32 participants with the sociodemographic features described above.

\section{Stage II: Training}

All the people that showed an interest in becoming elder natural mediators received training in the leisure centers. The training consisted in 14 sessions (30 hours total) in three different leisure centers. Right before the start of the first session, we distributed the "custom-made" instruments designed to establish baselines (before the intervention) and to assess the acquisition of knowledge at the end of the program from the participant's point of view. The contents addressed in these sessions had an eminently practical bias and dealt with the following:

1. Understanding conflict and its underlying needs, desires, and values.

2. Development of a vision and management of positive conflict in cohabitation.

3. Practice of social interactions and day-to-day positive communication.

4. Development of basic skills and functions of the mediator (active listening, selfconfidence, responsibility in the conflict, ease and understanding, cooperation, negotiation...).

5. Mediation stages: from initial positioning, to interests, to agreement.

\section{Stage III: Knowledge Transference}

Once the training program was completed, knowledge transference consisted of accompanying the 21 participants who decided to engage in awareness actions/activities in their own communities. These 21 participants were monitored by professional mediators (the ones in charge of the training program) in order to guarantee motivation and quality levels in the resulting actions.

The activities aimed at creating spaces in which to meditate and relate to the social environment, and their main actors were senior citizens who had participated and followed the training program.

And, finally, the activities carried out by the participants were presented in a formal festive event. 


\section{Tools}

To assess the skills learned during the workshop, a six-question self-assessment questionnaire was applied with a 0-to-10 rating. The questions referred to the degree in which the person perceived he/she possessed the following social skills, and they were formulated in the following statements:

1. Understands other people's needs, desires and values.2. Considers herself a good listener and communicator.

2. Facilitates understanding with other people.

3. Develops some skills towards cooperation and negotiation.

4. Assumes responsibility for his/her own actions and consequences.

5. Believes in the possibility to transform difficult situations.

Additionally, we included a yes/no question regarding whether participants would recommend the program to other potential users.

\section{Ethical Considerations}

All participants were informed in advance of the research purposes, and they were asked to give their informed consent to gather data for those purposes.

\section{RESULTS}

The analysis of the gathered information was made through the SPSS program (version 20). Specifically - given the sample's size and the procedure through which it was obtained,- the differences between the evaluations of mediating skills before and after the workshop were obtained through the Wilcoxon test $(T)$. Concerning the links between the skills evaluation and the sociodemographic variables, they were analyzed with the Kruskal-Wallis test $(H)$.

\section{Development of Mediating Social Skills}

Concerning the mediating skills that were assessed before the intervention (Table 2), the participants sensed they mostly could: assume responsibility for their own acts (and their consequences: $M=7.88, S D=1.31)$; listen to others and have the ability to communicate $(M=$ $7.38, S D=1.64)$; and understand other people's needs, desires, and values $(M=7.22, S D=$ 1.18). By contrast, the less valued mediating skill overall was the ability to cooperate and negotiate $(M=5.72, S D=2.59)$. This mediating skills assessment was also observed when doing the post intervention survey. In other words, once the workshop was completed, skills were valued the same way as they were at the beginning of the experience (same as Table 2)

When comparing evaluations made before and after the intervention, significant differences were obtained in three out of six reviewed skills (same as Table 2). The participants believed that after the workshop they improved in these areas: understanding other people's needs, desires, 
TABLE 2

Assessment of the Skills Included in the Workshop $(N=32)$

\begin{tabular}{|c|c|c|c|c|c|c|}
\hline \multirow[b]{2}{*}{ Skills } & \multicolumn{2}{|c|}{ Pre } & \multicolumn{2}{|c|}{ Post } & \multirow[b]{2}{*}{$\mathrm{T}$} & \multirow[b]{2}{*}{$\mathrm{P}$} \\
\hline & M & SD & M & SD & & \\
\hline Understands other people's needs, desires, and values & 7.22 & 1.18 & 7.86 & 1.28 & -2.029 & .042 \\
\hline Considers herself a good listener and communicator & 7.38 & 1.64 & 7.95 & 1.29 & -1.995 & .046 \\
\hline Facilitates understanding with other people & 6.65 & 1.22 & 7.33 & 1.68 & -2.213 & .027 \\
\hline Develops some skills towards cooperation and negotiation & 5.72 & 2.59 & 5.73 & 2.51 & 0.000 & 1.000 \\
\hline Assumes responsibility for his/her own actions and consequences & 7.88 & 1.31 & 7.86 & 1.78 & -.340 & .734 \\
\hline Believes in the possibility to transform difficult situations & 6.59 & 1.56 & 6.73 & 1.77 & -.242 & .809 \\
\hline
\end{tabular}

and values $(T=-2.029, p<.042)$; listening to others and communicating effectively ( $T=$ $-1.995, p<.046)$; and facilitating understanding with others $(T=-2.213, p<.027)$.

Skills included in the educational training, when paired with the sociodemographic variables, showed significant differences in four cases (nontabulated data); two in the initial assessment (pretest); the remaining two, upon concluding the program (after test). At the start of the program, we observed that mainly the people who reported being in good health considered themselves good listeners and communicators $(H=5.108 ; p<.078)$ and facilitating understanding with others $(H=8.843 ; p<.012)$. At the end of the program, the participants from downtown Barcelona showed a better understanding of other people's needs, desires, and values $(H=5.533$; $p<.063)$. In contrast, women showed a development of their cooperation and negotiation skills $(H=4.207 ; p<.040)$.

Also, concerning the question about satisfaction and whether they would recommend the program, the final score was 4.69 over 5 . Through conversations with the mediators, when asked about their favorite parts of the program, the participants expressed their wish for the program to continue in the future. They expressed their gratitude for the opportunity to learn about mediation, about its main communication skills, and they expressed a desire to keep learning things about mediation in the future.

\section{Actions/Activities Undertaken by the Participants}

Once the training was completed, the participants launched a total of 17 projects ( 8 in Santa Coloma, 7 in Manresa, and 2 in Barcelona, but out of these 17, only 3 in Santa Coloma, 5 in Manresa and 2 in Barcelona were successfully completed. So, 11 finished projects served to spread in the communities the concepts and procedures of mediation that the participants had learned during their training. These projects were mainly based on the organization of the following:

1. Lectures in senior centers.

2. Posters to spread mediation culture.

3. Talks with public and/or social institutions representatives.

4. Research on mediation resources available in the area.

5. Communication and active listening workshops.

6. Talks and debates to discuss conflict resolution through mediation. 


\section{DISCUSSION AND CONCLUSION}

The results of this study show that empowering senior citizens in mediation skills in leisure centers was useful as a procedure to boost skills in people who are aging in an active way. The study has contributed to the development of the application of mediation in senior citizens from an educational point of view. In that sense, mediation implementation in an emerging environment promotes conflict resolution through mediation and benefits inclusion and social commitment of senior citizens. We observe that mediation has proved once more a good educational option (Kardasis \& Dugan, 2004; Baruch \& Folger, 2005), given the degree of satisfaction expressed by the participants (4.69 over 5 ) and the wish they expressed to continue learning mediating social skills. This suggests that, when implementing this kind of programs in a leisure environment, relevant psychosocial benefits and satisfaction can be reached among the participants in accordance with previous studies (Cox \& Parsons, 1992; Fenge, 2006, 2010; Armadans, 2009). Furthermore, it is also likely that participants were imbued with mediation values concerning the peaceful building of social relationships in conflict situations (Lederach, 1998; Ury, 1999), given that 21 of them, once they finished the training stage, undertook and completed 11 projects in their communities or senior centers.

Concerning the main results obtained with the procedure, we found significant improvement in the following areas: accountability of personal actions in conflict situations (and their consequences: $M=7.88, S D=1.31)$; active listening and improved communication skills $(M=7.38$, $S D=1.64)$; understanding other people's needs, desires and values $(M=7.22, S D=1.18)$; and facilitating understanding with others $(T=-2.213, p<.027)$. This suggests that participants absorbed the basic and necessary social skills of the mediator figure (Wall, Stark, \& Standifer, 2001: 2012), which will allow them to act in conflict situations. They also developed the mediator personal power in line with the suggestions made by Cobb (1993) and other authors (Agusti-Panareda, 2005).

In short, we can state that the main practical implications of this study are based on this work representing a first effort of its kind, in a study context where mediation is still in a very early stage and needs to be encouraged. The results of the procedure inspire us to keep up the studies focused at empowerment training programs through mediation, and to continue along the lines of earlier works (Cox \& Parsons, 1992; Fenge, 2006, 2010; Schmitz, 1998; Bowman, 2000; Alzate et al., 2009; Armadans, 2009). It would be convenient to keep studying the potentiality of the positive benefits resulting from this implementation in the senior citizens context: conflict mediation as an empowering educational tool, especially in leisure situations (Kardasis \& Dugan, 2004; Baruch \& Folger, 2005), plus being able to apply it in other contexts.

However, we should also consider that the limits that this study presents are mainly linked to its design as an exploratory research. This kind of design does not allow us to establish general and final conclusions concerning the results obtained, even though the program's implementation reached its expected goals.

In conclusion, if the educational program worked among the active senior citizens, and we successfully empowered the senior mediator, maybe in the future this same kind of program could be developed and improved. This could be achieved by adapting the program to social environments where the elder people could really contribute an important social capital by providing their wisdom and experience. It is worthwhile to verify in future studies whether the development of social figures or natural helpers from a third party standpoint (Lederach, 
1998; Ury, 1999) are able to transfer knowledge to the community and have an impact in the creation and strengthening of social networks in the senior-citizen environment.

\section{FUNDING}

The authors express their thanks to Mar Vidal for his invaluable help in correcting the English language manuscript. The English language correction received the financial support of the PsicoSAO-Research Group in Social, Environmental, and Organizational Psychology (2014 SRG 992; Comissionat per a Universitats i Recerca del DIUE from the Generalitat de Catalunya).

\section{REFERENCES}

Agusti-Panareda, J. (2005). The possibility of personal empowerment in dispute resolution: Habermas, Foucault and community mediation. Research in Social Movements, Conflicts and Change, 26, 265-290.

Alzate, R., Malla, R., \& Godoy, A. (2009). Conflict situations in the socio-health sphere of aged people. Conflictology, 1, 35-39.

Armadans, I. (2009). Mediación transformativa y resolución de conflictos: apreciando la convivencia en el ámbito de las personas mayores [Transformative mediation and conflict resolution: Appreciating cohabitation in senior citizens environments]. In J. Giró Miranda (Ed.), Envejecimiento, Tiempo Libre y Gestión del Ocio [Ageing, free time and leisure management] (pp. 219-241). Logroño, Spain: Universidad La Rioja.

Armadans, I., Manzano, J., \& Soria, M. (2007). Envejecimiento y calidad de vida: análisis de los conflictos en personas mayores "activas" y en la convivencia en los centros de tiempo libre [Ageing and quality of life: Conflict analysis among active elder people and in cohabitation in leisure centers]. Revista Multidisciplinar de Gerontología, 17(1), $7-12$.

Armadans, I., Vilaseca, S., \& Quesada, C. (2010). La Mediación natural, las personas mayores y la comunidad: el proyecto 'Grands mediadors [Natural mediation, elder people and community: The Grands Mediadors Project]. In J. Giró Miranda (Ed.), Envejecimiento, conocimiento y experiencia [Ageing, knowledge and experience] (pp. 255275). Logroño, Spain: Universidad La Rioja

Baruch, R. A. B., \& Folger, J. P. (2005). The promise of mediation: The transformative approach to conflict. San Francisco, CA: Jossey-Bass.

Bernard, J. A. (2009). Ocio de las personas mayores: Un programa para el desarrollo de sus habilidades cognitivas, emocionales y sociales [Leisure in old age: A program for the development of their cognitive, emotional and social skills]. In J. Giró (coord.). Envejecimiento, Tiempo Libre y Gestión del Ocio (pp. 135-157). Logroño, Spain: Universidad La Rioja

Bertschler, P., \& Cocklin, L. (2004). Truce! Using elder mediation to resolve conflict among families, seniors and organizations (vol. 55). Lawrenceville, GA: NCS Publishing.

Bloche, M. G. (2005). Managing conflict at the end of life. New England Journal of Medicine, 352(23), $2371-2373$.

Boqué, M. C. (2013). La mediación como disciplina y como profesión. El perfil competencial del mediador [Mediation as a discipline and as a professional career. The skill profile of mediators]. In R. Castillejo (coord.), La mediación. Nuevas realidades [Mediation: New realities, new challenges]. Nuevos retos (pp. 20-56). Santiago de Compostela, Spain: Universidad de Santiago de Compostela.

Bowman, K. W. (2000). Communication, negotiation, and mediation: Dealing with conflict in end-of-life. Journal of Palliative Care, 16, 17-23.

Cobb, S. (1993). Empowerment and mediation: A narrative perspective. Negotiation Journal, 9(3), 245-259.

Codina, N., Pestana, J. V., \& Armadans, I. (2013). Physical activity (PA) among middle-aged women: Initial and current influences and patterns of participation. Journal of Women \& Aging, 25(3), 260-272. doi:10.1080/08952841. 2013.791605

Costa e Silva, A. M. (2012). Education, citizenship and mediation. Citizenship, Social and Economics Education, 11(1), $2-10$. 
Cox, E. O., \& Parsons, R. G. (1992). Senior-to-senior Mediation service project. The Gerontologist, 32(3), 420-422.

Craig, Y. (2000). The multicultural Elder Mediation Project (EMP): Empowerment for older, disabled, and mentally frail persons. In M. Liebmann (Ed.), Mediation in context (pp. 202-210). London, UK: Jessica Kingsley Publishers.

Cusack, S. A. (1998). Leadership in Seniors' Centres: Power and empowerment in relations between seniors and staff. Education and Ageing, 13, 49-66.

Cusack, S. A. (1999). Critical educational gerontology and the imperative to empower. Education and Ageing, 14(1), 21-37.

Fenge, L. (2006). Empowering older volunteers: Learning to research. Research Policy and Planning, 24 (1): 13-23.

Fenge, L. (2010). Striving towards inclusive research: An example of participatory action research with older lesbians and gay men. The British Journal of Social Work, 40(3), 878-894.

Gary, S. N. (1997). Mediation and the elderly: Using mediation to resolve probate disputes over guardianship and inheritance. Wake Forest Law Review, 32, 397.

Hedeen, T., Raines, S. S., \& Barton, A. B. (2010). Foundations of mediation training: A literature review of adult education and training design. Conflict Resolution Quarterly, 28(2), 157-182.

Kardasis, A., \& Dugan, J. (2004). Elder decisions in elder mediation. Retrieved from www.mediate.com/articles/ dugan1.cfm

Kleiber, D. A., Walker, G. J., \& Mannell, R. C. (2011). A social psychology of leisure (2nd ed.). State College, PA: Venture.

Lederach, J. P. L. (1998). Construyendo la paz. Reconciliación sostenible en sociedades divididas. [Building peace. Sustainable reconciliation in divided societies] Gernika, Spain: Gernika Gogoratuz.

Luppi, E. (2009). Education in old age: An exploratory study. International Journal of Lifelong Education, 28(2), 241-276.

Luppi, E. (2010). Autonomy and citizenship in the late third age. Educational Gerontology, 36, 872-892.

Marhánkova, J. H. (2010). Leisure in old age: Disciplinary practices surrounding the discourse of active ageing. International Journal of Ageing and Later Life, 6(1), 5-32.

Maxwell, J. P. (1997). Conflict management and mediation training: A vehicle for community empowerment? Conflict Resolution Quarterly, 15(2), 83-96.

Morata, T., \& Palassí (2012). Ocio y participación social de las personas mayores. Evaluación de un programa de Animación Sociocultural y Desarrollo Comunitario en la ciudad de Granollers [Leisure and social commitment among the elderly. Assessment of a Sociocultural Promotion and Community Development Program in the city of Granollers]. Educación social: Revista de intervención socioeducativa, 50, 67-90

Munuera Gómez, M. P. (2006). Mediación en situaciones de dependencia: Conceptos claves y marco jurídico relevante [Mediation in dependence situations: Key concepts and relevant legal frame]. Acciones e Investigaciones Sociales. Zaragoza, Spain: Universidad de Zaragoza. Retrieved from: http://eprints.ucm.es/5669/1/Munuera_Gomez.pdf

Munuera Gómez, M. P., \& Rondón García, L. M. (2010). Mediación y Resolución de conflictos con personas en situación de dependencia [Mediation and conflict resolution in dependent people]. In C. Alemán Bracho (Ed.), Dependencia y servicios sociales (pp. 323-360). Madrid, Spain: Aranzadi.

Nimrod, G. (2007). Retirees' leisure: Activities, benefits, and their contribution to life satisfaction. Leisure Studies, 26, 65-80.

Ogg, J. (2005). Social exclusion and insecurity among older Europeans: The influence of welfare regimes. Ageing and Society, 25, 69-90.

Schmitz, S. J. (1998). Mediation and the elderly: What mediators need to know. Mediation Quarterly, 16(1), 71-84.

Ury, W. L. (1999). Getting to peace transforming conflict at home, at work and in the world. London, United Kingdom: Viking Penguin.

Wall, J. A., \& Dunne, T. C. (2012). Mediation research: A current review. Negotiation Journal, 28(2), 217-244.

Wall, J. A., Stark, J. B., \& Standifer, R. L. (2001). Mediation. A current review and theory development. Journal of Conflict Resolution, 45(3), 370-391.

Walter, U., Schneider, N., \& Plaumann, M. (2008). Empowerment for the elderly. Gesundheitswesen, 70(12), 730-735.

Zimmerman, M. A., Israel, B. A., Schulz, A., \& Checkoway, B. (1992). Further explorations in empowerment theory: An empirical analysis of psychological empowerment. American Journal of Community Psychology, 20(6), 707-727. 